Homer CSE, Passant L, Kildea S, Pincombe J, Thorogood C., Leap, N, Brodie, PM. (2007), The development of national competency standards for the midwife in Australia. Midwifery 23 (4): 350-360.

\title{
THE DEVELOPMENT OF NATIONAL COMPETENCY STANDARDS FOR THE MIDWIFE IN AUSTRALIA
}

\section{Caroline SE Homer RM RN MN PhD}

Professor of Midwifery, Centre for Midwifery and Family Health, Faculty of Nursing Midwifery and Health, University of Technology Sydney.

\section{Lyn Passant RN RM MMid}

Project Officer, Centre for Midwifery and Family Health, Faculty of Nursing

Midwifery and Health, University of Technology Sydney.

\section{Sue Kildea RN RM BHlthSc (Hons) PhD}

Senior Research Officer, Centre for Midwifery and Family Health, Faculty of Nursing Midwifery and Health, University of Technology Sydney.

\section{Jan Pincombe RM RN MAppSc PhD}

Professor of Midwifery and Program Director of Midwifery, Department of Nursing and Midwifery, University of South Australia.

\section{Carol Thorogood RN RM MPhil PhD}

Senior Lecturer in Midwifery, School of Nursing and Public Health, Edith Cowan University, Perth. 


\section{Nicky Leap RM MSc DMid}

Director of Midwifery Practice, South Eastern Sydney and Illawarra Area Health Service and Associate Professor, Centre for Midwifery and Family Health, Faculty of Nursing, Midwifery and Health, University of Technology Sydney.

\section{Pat M Brodie RN RM MN DMid}

Professor of Midwifery Practice Development, Sydney South West Area Health Service and University of Technology Sydney.

Keywords: Midwifery, competency standards, Australia

\section{Contact details}

Caroline Homer

Centre for Midwifery and Family Health, Faculty of Nursing Midwifery and Health

University of Technology Sydney

PO Box 123

Broadway NSW Australia 2007

Tel 61295142977

Fax 61295142977

Email: Caroline.Homer@uts.edu.au

Offprint requests to CSEH 


\title{
THE DEVELOPMENT OF NATIONAL COMPETENCY STANDARDS FOR THE MIDWIFE IN AUSTRALIA
}

\begin{abstract}
Objective: To develop and validate national competency standards for midwives in Australia. This study was part of a commissioned national research project to articulate the scope of practice of Australian midwives and to develop national competency standards to assist midwives to deliver safe and competent midwifery care.
\end{abstract}

Design: A multi-method, staged approach collected data through a literature review, workshop consultations, interviews, surveys and written submissions in order to develop national competency standards for Australian midwives. Subsequently, direct observation of practice in a range of settings ensured validation of the competencies.

Setting: Maternity care settings in each state and territory in Australia.

Participants: Midwives, other health professionals and consumers of midwifery care.

Findings: The National Competency Standards for the Midwife were developed through research and consultation prior to being validated in practice.

Key conclusions: The national competency standards are currently being implemented into education, regulation and practice in Australia. These will be 
minimum competency standards required of all midwives who seek authority to practise as a midwife in Australia. It is expected that all midwives will demonstrate that they are able to meet the competency standards relevant to the position they hold.

Implications for practice: The competency standards establish a national standard for midwives and reinforce responsibility and accountability in the provision of quality midwifery care through safe and effective practice. In addition, individual midwives may use the competency standards as the basis of their ongoing professional development plans. 


\section{Introduction}

The Australian Nursing and Midwifery Council (ANMC) was established to facilitate a national approach to nursing and midwifery regulation. The ANMC works with the eight state and territory nursing and midwifery regulatory authorities (NMRAs) in Australia to develop nursing and midwifery standards that are flexible, effective and responsive to the health care requirements of the Australian community. In 2004, the ANMC commissioned a major project to research the role and scope of practice of midwives in Australia and to develop national competency standards for practice.

National competency standards for use in the regulation of midwives had not previously been undertaken by the ANMC for midwives. There was no national consistency about the competency standards for midwifery practice. Different states and territories have adopted different competency standards. Some adopted the standards developed by the Australian College of Midwives while others developed their own standards.

This aim of this paper is describe how the national competency standards for the midwife in Australia were developed using a multi-method and consultative approach (Sandelowski, 2000).

\section{Competency standards}

The definition of competence has been discussed widely in the professional literature (Gonczi, Hager, \& Oliver, 1990; Pearson, Fitzgerald, \& Walsh, 2002; Redfern, Norman, Calman, Watson, \& Murrells, 2002). Competence is said to describe the set 
of characteristics or attributes that underlie and enable capable practice in an occupation (Heywood, Gonzi, \& Hager, 1992). Competencies describe a comprehensive profile of the knowledge, skills and professional behaviours that can be expected for a particular professional group (Fullerton, Severino, Brogan, \& Thompson, 2003). The International Confederation of Midwives (ICM) defines competencies as 'the knowledge, skills and behaviours required of the midwife for safe practice in any setting' (ICM, 2002). Previous work in Australia defined the concept of midwifery competency as 'embodying quality practice, and the knowledge, skills and attitudes required within the specified midwifery practice and statutory context' (Cutts, 1995). The earlier developmental work in Australia produced ‘competency standards’ for midwifery, building upon these definitions of competence, to describe the standards of practice set by the profession for its members and society (Glover, 1999).

\section{The history of midwifery competency standards in Australia}

During the 1990s, the National Executive Committee of the Australian College of Midwives led the initial development of midwifery competencies using an expert panel approach (Glover, 1999). Midwifery competency standards were developed against a background that believed at the time that "nurses entering midwifery were expected to function according to [registered nurses] competency” (Cutts 1994; p. 19). The Australian College of Midwives competency standards were not universally adopted in Australia for use in regulation, education or employment as there was some disagreement across jurisdictions. Some jurisdictions adopted the Australian College of Midwives’ standards while others developed their own standards and others continued to apply the competency standards for a registered nurse to 
midwives. In the past five years, there have been considerable changes in midwifery education and practice in Australia. These include the introduction of midwifery models of care and the introduction of the three-year Bachelor of Midwifery degree as an alternative entry to midwifery practice. Therefore, it was timely to develop national competency standards for midwives, which would be validated in practice, and informed by research.

\section{National Competency Standards for the Midwife}

The National Competency Standards for the Midwife were designed for a range of purposes as defined by the peak regulatory body for nursing and midwifery in Australia, the ANMC. These purposes were defined by the ANMC at the outset of the research:

- $\quad$ Communicate to consumers, professions and others the competency standards they can expect of midwives;

- Inform the approval or accreditation processes of curricula for midwifery education;

- $\quad$ Determine the eligibility for authority to practise midwifery for people who have graduated from midwifery courses in Australia or elsewhere;

- Assess midwives who wish to return to work after being out of the workforce for a defined period;

- Assess qualified midwives who are required to show that they demonstrate continuing competence relevant to the position that they hold;

- $\quad$ Enable individual midwives to identify their ongoing professional development plans ; and 
- $\quad$ Facilitate mutual recognition across Australian states and territories and internationally.

\section{Methods}

Governance and ongoing consultation

The research was governed by a Project Management Committee (PMC) and there was ongoing consultation with this group and a Reference Group. The PMC was convened by the ANMC and was composed of nine representatives from the regulatory authorities, the Australian College of Midwives and the national industrial organisation for nurses and midwives. The Reference Group was the Australian National Education and Standards Taskforce (ANEST), an established group of the Australian College of Midwives, comprising 10 experts in midwifery education and practice from each state and territory. The Reference Group provided review, comment and feedback throughout the project. The PMC also provided feedback at each Round of the consultation and validation process.

Initial development of the competency standards

A literature review was undertaken to identify Australian and international literature regarding midwifery competency standards. The review included literature from established databases such as CINAHL, MIDIRS and Medline as well as conference presentations, publications and national and international reports from regulatory and professional bodies. Key words that were included in the literature search included: midwifery; midwife; midw*; certified nurse-midwife; competency, professional competency; competence; competenc*; and, standards. Key documents from a number of countries and organisations were also identified (Table 1). 


\section{Round 1 of consultation}

From the literature review, a draft of the competency standards (known as Round 1) was developed as a starting point for the consultation process. The draft had an overarching framework, that is, 'woman centred care', and was underpinned by primary health care principles. Woman centred care is a concept that implies that midwifery care:

- $\quad$ is focussed on the woman's individual, unique needs, expectations and aspirations, rather than the needs of institutions or professions;

- recognises the woman's right to self determination in terms of choice, control, and continuity of care;

- $\quad$ encompasses the needs of the baby, the woman's family, significant others and community, as identified and negotiated by the woman herself;

- follows the woman between institutions and the community, through all phases of pregnancy, birth and the postnatal period; and,

- $\quad$ is 'holistic' - addresses the woman’s social, emotional, physical, psychological, spiritual and cultural needs and expectations (Leap, 2000). Primary health care principles encompass equity, access, and the provision of services based on need; they include community participation, collaboration and community based care. Primary health care involves using approaches that are affordable, appropriate to local needs and sustainable (WHO, 1978).

The draft competency standards included domains, competency units, elements and cues. There were four domains. A domain is defined as an organised cluster of competencies that characterise a central aspect of midwifery practice. Within each of 
the domains were competencies. A competency represents a stand-alone function or functional area underlying some aspect of professional performance. Within each competency were elements. An element is a sub-section of the competency unit. The elements contained examples of competent performance known as cues. These were neither comprehensive nor exhaustive.

The Round 1 document was circulated to the Project Management Committee and the Reference Group and discussed at face to face meetings. Changes were made as necessary after these meetings. This next version was known as Round 2.

\section{Round 2 of consultation}

The Round 2 document was used in consultation during eight workshops held in each state and territory of Australia and included participation from 153 midwives, student midwives and policy makers. This consultation process was designed to target midwives who worked in different settings and models of care. The eight workshops were held in a range of settings including three capital cities, one major regional city, two smaller regional towns, one rural town and one remote town. Using this approach, midwives from metropolitan, regional, rural and remote settings, as well as from government and private institutions, were included. This represented the diversity of midwives in Australia. Feedback from the workshops was used to develop the next version of the competency standards (known as Round 3).

\section{Round 3 of consultation}

The Round 3 draft was used in wider consultation including a website-based survey, an invitation for written submission, an international review and telephone interviews 
with key stakeholders. There were 66 submissions to the website survey and four written submissions from groups of midwives or professional organisations. The respondents to the website survey were from across the country (Table 2) and represented midwives working in a diverse range of practice areas and roles (Table 3).

Invited experts from New Zealand and the United Kingdom reviewed the competency standards for international comparability. Australia has a 'Trans-Tasman agreement' with regulatory authorities in New Zealand, which means that it was essential that the competency standards would be appropriate under this agreement of mutual recognition.

Telephone interviews were held with key people nominated by each of the eight nurse and midwife regulatory authorities in Australia as well as six professional and industrial organisations representing midwives and providers of maternity care. In particular, contribution by the regulatory authorities was essential to the overall aim of ensuring national consistency of competency standards throughout the country. These interviews also served as a means to consult and receive feedback about the draft document and to inform the different authorities about the process and the outcome.

Feedback from the Round 3 processes of consultation was used to further refine the competency standards and the draft document. This version was known as the Round 4 and was used for the validation of the competency standards in practice.

Round four - Validating the competency standards 
The validation method included direct observations and interviews in seven sites around Australia. The sites were chosen to ensure that there was broad representation from metropolitan (tertiary and non-tertiary hospitals), rural and remote settings as well as private, public and independent arenas (Table 4). The full range of midwifery practice was studied in antenatal, labour and birth, postnatal and community settings. Midwifery models of care such as independent practice, team midwifery and midwifery caseload practice were included, as well as traditional models of maternity care in hospital settings.

\section{Sample}

Purposive sampling in each setting was undertaken to ensure the recruitment of a wide range of midwives of diverse ages, with different levels of experience and education, working in a variety of models of care. Involvement in the study was voluntary.

\section{Procedure}

Approval from the Human Research Ethics Committees was obtained from the seven sites and the three universities involved in the study. A presentation was prepared and sent to each site prior to the observations. This explained the purpose of competency standards and described the study. Participating midwives and women were provided with an information sheet and asked to sign a consent form prior to the observations. The observer then worked alongside each participating midwife. Due to the sensitive nature of midwifery care, there were occasions where it was not possible, or appropriate, to continue with the observations. In these situations, there was an opportunity to talk with the midwife rather than continue with observation. Following each observation session, a short (10-15 minute) interview was conducted with the 
midwife to further discuss the practice observed. This approach resulted in a number of direct and non-direct observations. Each direct observation of practice included an interview (non-direct observation) with the midwife/midwives involved in the situation to verify the inferences made by the observer.

A standard format for data collection was designed. There were two parts to the data collection sheet:

- $\quad$ Part 1. An initial section collected information about the setting and time period and demographic data relevant to the midwife being observed. The data including age, years of experience as a midwife; time in the current setting; and educational level. All identifying data were coded to protect anonymity.

- $\quad$ Part 2. The observer recorded field notes during observations detailing what was seen and discussed. The field notes described the skills, knowledge and attitudes demonstrated or expressed by the midwife as she practised and more information was included once the interview with the midwife had occurred.

The observations and interviews were undertaken by one person to ensure consistency. The observer was a midwife who had extensive clinical experience and was knowledgeable about the competency standards being validated. The observation process, methods and tools, including the data collection sheet, were all pre-tested with the observer and another member of the research team in a practice situation, to ensure that they were effective and feasible.

\section{Ethical considerations}


Observations were undertaken as non-participant observation. Therefore, while the observer was a midwife, she was not able to provide midwifery care, give advice to midwives or women, or to alter the provision of care in any way. The observer did not intervene if she observed care that she believed to be non-evidence based or contrary to best practice. The only exception was when the care was deemed to be high risk or unsafe. When this occurred, the observer was instructed to remove herself as a 'researcher' and to seek assistance from the staff. This occurred on three occasions although none eventuated in mishap or detriment to the woman or midwife.

\section{Analysis}

Qualitative and quantitative approaches were used to analyse the data obtained from the observations. The quantitative data included demographic data describing the sample of midwives. Qualitative data included field notes and interviews.

Two team members read the field notes to develop an overall sense of the themes in relation to the competency standards and more broadly, to midwifery practice. Data were then coded into text units or episodes (short phrases), which described what was occurring in each event, that is, the skills, knowledge and attitudes that were demonstrated. The episodes were then allocated to each competency element that best reflected the intent of the skills, knowledge and attitude for midwifery practice.

A third member of the research team reviewed the coding and verified the allocation, making alterations where necessary. Re-allocation was required in only a small number of cases (less than 10 cases). A matrix was developed to map how each of the competency elements were supported by the observations. 


\section{Findings}

\section{Validation process}

In total, 42 midwives were approached to participate with 40 giving consent. The reasons given for non-participation were: (1) not interested in the project; and, (2) a newly graduated midwife who felt she would be 'judged' despite assurances this would not be the case. More than half of the participants were between 40 and 50 years of age, around two-thirds were in metropolitan areas and worked in hospital settings and three-quarters had hospital-based certificates in midwifery. The remainder were educated through university programmes. This sample is representative of the midwifery profession in Australia at the time of the study.

\section{Number of times episodes observed / validated}

In total, there were 533 direct and non-direct episodes observed. Some episodes (direct or non direct) were linked to multiple elements with the competency standards. There were a total of 782 occurrences of elements linked to the 533 episodes. Each competency standard was identified within the validation process.

The analysis confirmed the competency standards as being applicable to the practice of midwives in Australia. Each element was observed in practice, although not every midwife demonstrated every element during the specific observations period, as these were often limited. 
A number of small changes were made as a result of the validation. Duplication was found in a number of places and competencies were moved or altered accordingly. One element (relating to management and leadership) was found not to fit in the domain it originally appeared in (Primary Health Care) and was therefore moved. Two elements were added as a result of the validation process - one on delegation and another on management of care.

Organisation of the final National Competency Standards for the Midwife

The four domains are:

- Domain 1 - Legal and Professional Practice - contains the competencies that relate to legal and professional responsibilities including accountability, functioning in accordance with legislation affecting midwifery and demonstration of leadership.

- Domain 2 - Midwifery Knowledge and Practice - contains the competencies that relate to the performance of midwifery practice including assessment, planning, implementation and evaluation. Partnership with the woman is included in this domain.

- Domain 3 - Midwifery as Primary Health Care - contains the competencies that relate to midwifery as a public health strategy. Included are the principles of primary health care, notions of self-determination for women and the protection of individual and group rights.

- Domain 4 - Reflective and Ethical Practice - contains the competencies relating to self-appraisal, professional development and evidence based practice. 
The final National Competency Standards for the Midwife are provided in Table 6. This Table includes the competencies and the elements.

\section{Discussion}

This research has a number of limitations. It was not possible to obtain the views of all Australian midwives during the development process. It is possible that only midwives who were informed and aware of the project or those who had information technology skills (that is, could use the internet) choose to participate. While this is acknowledged, significant efforts were made to ensure that as many midwives as possible could contribute. This included open invitations to workshops, information presented at state conferences and professional forums, information in professional newsletters, which were widely distributed, availability of an on-line survey form and an invitation for written submissions. The Reference Group also provided an important contribution from midwifery leaders in education and practice roles across the country and the PMC ensured input from leaders in regulation and professional matters.

The sample size was guided by the number of midwives who participated, the number of sites for consultation and validation and the timeframe. It is difficult to determine whether the sample size for the validation is adequate, however, it was encouraging that all the competency elements were identified in practice although not every one with each midwife. The time frame for the study also meant that it was not possible to validate the competency standards in more practice settings. The sample included in the validation process, did, however, represent the broad range of midwives who work in maternity care in Australia. Each state and territory was represented and 
respondents identified working in a range of models of care, including public and private hospital maternity units and midwifery continuity of care schemes. These are broadly representative of the models of care options available in Australia.

Despite these limitations, the findings have relevance for midwifery practice. The National Competency Standards for the Midwife were developed from existing literature and documents and have been progressively developed through four rounds of consultation, discussion and validation. The validation process demonstrated that the National Competency Standards for the Midwife are valid for midwifery practice in Australia. The changes undertaken as a result of the validation process have further strengthened the applicability of the competency standards and have ensured that they are relevant to midwives who work in many diverse settings across the country. This is also the first time that Midwifery as Primary Health Care (Domain 3) and Actively supports midwifery as a public health strategy (Competency 9) have been so explicitly identified within national competency standards for midwives. This is in line with recent international developments which have identified that midwifery has a significant contribution to make in terms of primary health, public health policy and health gain for women and their babies (O Luanaigh \& Carlson, 2005).

Certain challenges became evident during the development and validation of the National Competency Standards for the Midwife. An inability to use or fulfil all the competency standards, due to system and organisational barriers, was identified by a number of respondents. Examples were given where midwives were aware of bestpractice evidence, but were often unable to practise accordingly due to institutional restrictions and working arrangements. Ongoing work in Australia is seeking to 
address these issues for midwives and maternity care provision. It is expected that the ANMC National Competency Standards for the Midwife (2006) will assist with this process and debate.

There is a role for NMRAs to require midwives to show their continuing competence to practise. Professional standards, such as competency standards, are for the protection of the public interest (National Nursing and Nursing Education Taskforce, 2005). The requirement for practitioners to demonstrate that they are keeping up-todate and are competent to practise is a worldwide issue. Inconsistencies in regulation across Australia mean that national application will be challenging. Legislative requirements regarding proof of competence vary in each jurisdiction for both nursing and midwifery (Brodie \& Barclay, 2001; Pearson, Fitzgerald, Walsh, \& Borbasi, 2002) and this will impact on the application of the competency standards. In jurisdictions where there is an emphasis on declaring 'competence to practise' according to national competency standards, the uptake will be greater than in jurisdictions where no such impetus exists. Incorporation of the competency standards into employment contracts, position descriptions and performance appraisals will assist with greater uptake, as will the use of the standards in the accreditation of midwifery education programmes and other regulatory practices.

Finally, the issue of specific, versus broad, competency standards was identified and debated throughout the research process. A small number of respondents in the study wanted competency standards that were much more specific and that detailed what a midwife was expected to be able to do. This approach is in keeping with the Essential Competencies for Midwifery Practice developed recently by the ICM (Fullerton, 
Severino, Brogan, \& Thompson, 2003; Fullerton \& Thompson, 2005; ICM, 2002). However, the majority of respondents, the ANMC and the NMRAs, did not support this approach. In addition, the competency documents reviewed from other countries, with one exception, did not support a specific and detailed approach. The National Competency Standards for the Midwife, therefore, take a broad approach rather than a specific or task-focussed approach. The interpretation that some respondents had about the purpose of competency standards, that is, a specific list of tasks or skills, reflects the need for an education program to accompany the release of the National Competency Standards for the Midwife. The competency standards are due to be reviewed in three years and it is possible that they may evolve in line with new understandings and national application.

\section{Conclusion}

This research has developed and validated the National Competency Standards for the Midwife in Australia. These will establish a national benchmark for midwives and reinforce responsibility and accountability in providing quality midwifery care through safe and effective work practice.

A lack of understanding about the structure, purpose and application of competency standards was evident in this research. Dissemination of the National Standards should include education about the purpose of competency standards and how they are used in practice. A strategy for the implementation is important to ensure that the standards are embedded into practice, education and regulatory settings. 
A copy of the ANMC National Competencies for the Midwife (2006) are available from the Australian Nursing and Midwifery Council. http://www.anmc.org.au/ 


\section{Acknowledgments}

We thank the midwives, consumers, managers, students, educators and others who participated in this research. We acknowledge the contribution of our Reference Group and the international technical advisors, Dr Sally Pairman from the New Zealand Midwifery Council and Professor Diane Fraser from the University of Nottingham in the United Kingdom. We thank Joanna Leonard from the University of Technology Sydney for assistance in preparation of this manuscript. This research was funded by the Australian Nursing and Midwifery Council. 
Table 1: Key documents used in initial literature search

ACMI Competency Standards for Midwives (ACMI, 2001a)

ACMI Code of Ethics (ACMI, 2001b)

Essential Competencies for Midwifery Practice (ICM, 2002);

ANC National Competency Standards for the Registered Nurse (ANC, 2000)

New Zealand Competencies for Entry to the Register of Midwives (Midwifery

Council of New Zealand, 2004);

United Kingdom Midwifery Competencies (Nursing and Midwifery Council, 2001);

Council for Remote Area Nurses of Australia Nurse Competencies (CRANA, 2001);

Core Competencies of the College of Midwives of Ontario (College of Midwives of

Ontario, 1994)

Baby Friendly Initiative - Practice Standards for Midwives (UNICEF, 2002). 
Table 2: Website survey respondents - State or territory of residence

\begin{tabular}{lc}
\hline State or territory & $\mathbf{N ~ ( \% )}$ \\
& $\mathbf{N = 6 6}$ \\
\hline Victoria & $18(27)$ \\
New South Wales & $17(26)$ \\
Queensland & $10(15)$ \\
South Australia & $8(12)$ \\
Western Australia & $6(9)$ \\
Northern Territory & $4(6)$ \\
Tasmania & $2(3)$ \\
Australian Capital Territory & $1(2)$ \\
\hline
\end{tabular}


Table 3: Website survey respondents - role of respondents

\begin{tabular}{lc}
\hline Role of respondent & $\mathbf{N ~ ( \% ) ~}$ \\
& $\mathbf{N = 6 6}$ \\
\hline Midwife in Maternity Unit & $27(41)$ \\
Management & $11(17)$ \\
Midwifery consultant & $8(12)$ \\
University education & $6(9)$ \\
Independent practice & $5(8)$ \\
Education - Hospital & $4(6)$ \\
Research & $4(6)$ \\
Community-based midwifery & $1(2)$ \\
\hline
\end{tabular}


Table 4: Sites for validation of competency standards and reason for inclusion

\begin{tabular}{|c|c|}
\hline Site & Reason for inclusion \\
\hline Tertiary women’s hospital & $\begin{array}{l}\text { Tertiary metropolitan centre with } 4000 \text { births per } \\
\text { annum. Range of models of care including caseload } \\
\text { practice, antenatal education, antenatal clinics and } \\
\text { ward, labour ward and birth centre, postnatal wards } \\
\text { and community care. }\end{array}$ \\
\hline $\begin{array}{l}\text { General hospital with maternity } \\
\text { section in a capital city }\end{array}$ & $\begin{array}{l}\text { Non-tertiary metropolitan centre with } 2000 \text { births } \\
\text { per annum. Range of models of care providing } \\
\text { midwifery and medical care including antenatal } \\
\text { clinic, antenatal ward, labour ward, postnatal ward, } \\
\text { and community midwifery. }\end{array}$ \\
\hline $\begin{array}{l}\text { Birth centre located within a } \\
\text { general hospital in a capital city }\end{array}$ & $\begin{array}{l}\text { Non-tertiary metropolitan centre with a birth centre } \\
\text { that has } 400 \text { births per annum. }\end{array}$ \\
\hline Smaller hospitals in a rural area & $\begin{array}{l}\text { Four rural hospitals with a total of } 1600 \text { births per } \\
\text { annum. The hospitals have a range of models of } \\
\text { care including GP-led care. }\end{array}$ \\
\hline Private hospital in a capital city & $\begin{array}{l}\text { Private maternity unit in a busy private hospital } \\
\text { with } 2400 \text { births per annum. }\end{array}$ \\
\hline Private midwifery practice & $\begin{array}{l}\text { A midwife in an independent practice with a } \\
\text { caseload of } 100 \text { women per annum. }\end{array}$ \\
\hline Remote setting & $\begin{array}{l}\text { A midwife providing antenatal and postnatal care to } \\
30-40 \text { women per annum in a remote Aboriginal } \\
\text { community in central Australia. }\end{array}$ \\
\hline
\end{tabular}


Table 5: Matrix to demonstrate the number of times each competency element was observed during validation

\begin{tabular}{|c|c|c|c|}
\hline Competency and element & $\begin{array}{c}\text { Number of } \\
\text { times } \\
\text { observed }\end{array}$ & Competency and element & $\begin{array}{c}\text { Number of } \\
\text { times } \\
\text { observed }\end{array}$ \\
\hline Competency 1 & & Competency 6 & \\
\hline - Element 1.1 & 11 & - Element 6.1 & 19 \\
\hline - $\quad$ Element 1.2 & 28 & - $\quad$ Element 6.2 & 10 \\
\hline - $\quad$ Element 1.3 & 28 & Competency 7 & \\
\hline - $\quad$ Element 1.4 & 14 & - $\quad$ Element 7.1 & 24 \\
\hline Competency 2 & & - $\quad$ Element 7.2 & 8 \\
\hline - Element 2.1 & 19 & Competency 8 & \\
\hline - $\quad$ Element 2.2 & 10 & - $\quad$ Element 8.1 & 33 \\
\hline - $\quad$ Element 2.3 & 17 & - $\quad$ Element 8.2 & 22 \\
\hline - $\quad$ *Element 2.4 & 11 & - $\quad$ Element 8.3 & 15 \\
\hline - $\quad$ Element 2.5 & 8 & Competency 9 & \\
\hline Competency 3 & & - Element 9.1 & 22 \\
\hline - $\quad$ Element 3.1 & 45 & - $\quad$ Element 9.2 & 13 \\
\hline - $\quad$ Element 3.2 & 20 & Competency 10 & \\
\hline - $\quad$ Element 3.3 & 23 & - $\quad$ Element 10.1 & 16 \\
\hline Competency 4 & & Competency 11 & \\
\hline - $\quad$ Element 4.1 & 33 & - Element 11.1 & 13 \\
\hline - $\quad$ Element 4.2 & 23 & Competency 12 & \\
\hline - $\quad$ *Element 4.3 & 5 & - $\quad$ Element 12.1 & 11 \\
\hline Competency 5 & & - Element 12.2 & 12 \\
\hline - $\quad$ Element 5.1 & 24 & Competency 13 & \\
\hline - $\quad$ Element 5.2 & 42 & - Element 13.1 & 18 \\
\hline - $\quad$ Element 5.3 & 46 & - $\quad$ Element 13.2 & 22 \\
\hline - $\quad$ Element 5.4 & 40 & Competency 14 & \\
\hline - $\quad$ Element 5.5 & 23 & - Element 14.1 & 23 \\
\hline - $\quad$ Element 5.6 & 11 & - Element 14.2 & 20 \\
\hline
\end{tabular}

*Elements 2.4 and 4.3 were added as a result of the consultation and validation process. Data collected previously were then re-analysed and included in the final data. 
Table 6: Australian Nursing and Midwifery Council’s National Competency Standards for the Midwife (ANMC, 2006)

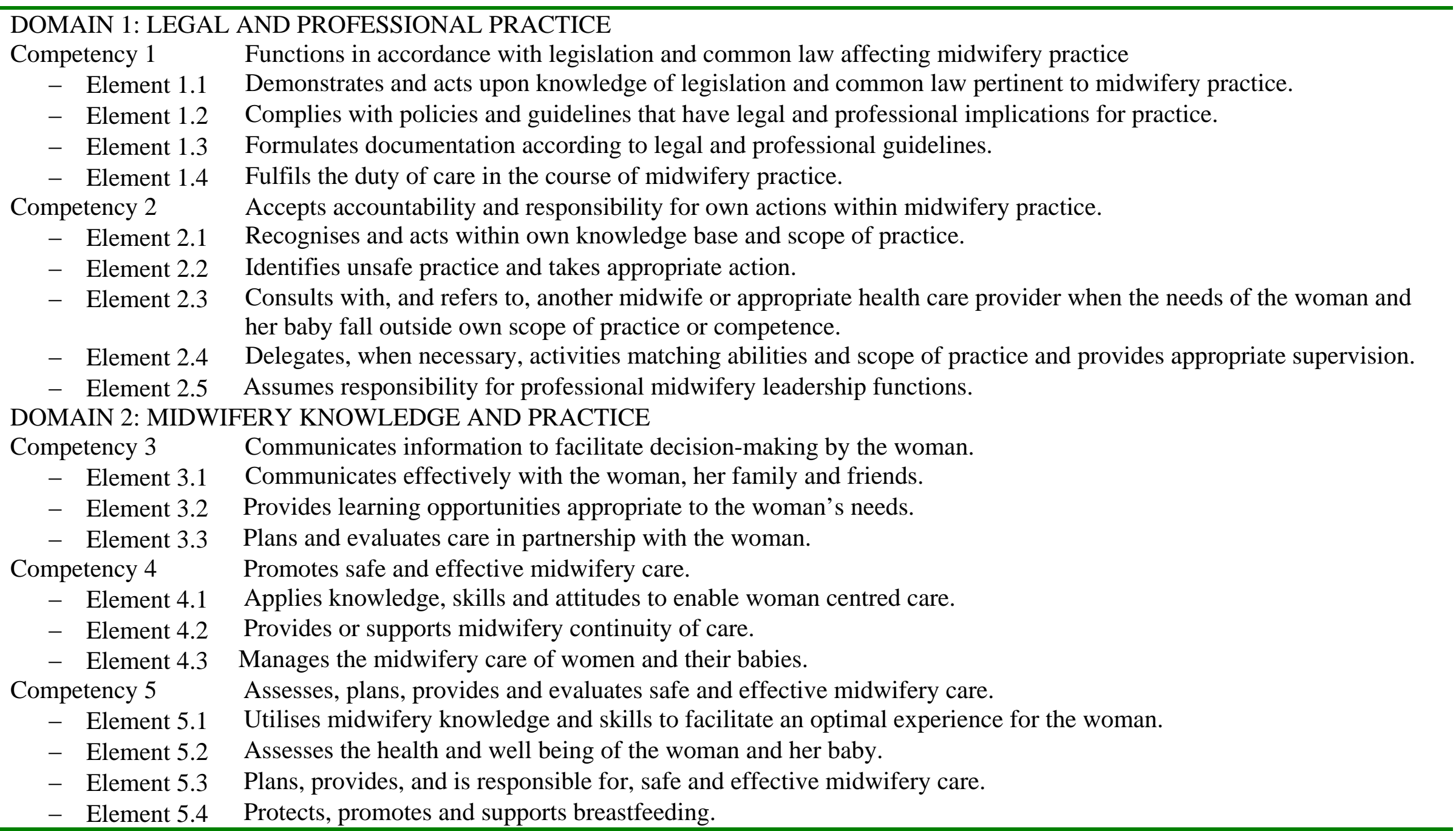


- $\quad$ Element 5.5 Demonstrates the ability to initiate, supply and administer relevant pharmacological substances in a safe and effective manner within relevant state or territory legislation.

- Element 5.6 Evaluates the midwifery care provided to the woman and her baby.

Competency $6 \quad$ Assesses, plans, provides and evaluates safe and effective midwifery care for the woman and/or baby with complex needs.

- Element 6.1 Utilises a range of midwifery knowledge and skills to provide midwifery care for the woman and/or her baby with complex needs as part of a collaborative team.

- Element 6.2 Recognises and responds effectively in emergencies or urgent situations.

DOMAIN 3: MIDWIFERY AS PRIMARY HEALTH CARE

Competency $7 \quad$ Advocates to protect the rights of women, families and communities in relation to maternity care.

- Element 7.1 Respects and supports women and their families to be self-determining in promoting their own health and well-being.

- Element 7.2 Acts to ensure that the rights of women receiving maternity care are respected.

Competency 8

Develops effective strategies to implement and support collaborative midwifery practice.

- Element 8.1 Demonstrates effective communication with midwives, health care providers and other professionals.

- Element 8.2 Establishes, maintains and evaluates professional relationships with other health care providers.

Competency $9 \quad$ Actively supports midwifery as a public health strategy.

- Element 9.1 Advocates for, and promotes midwifery practice, within the context of public health policy.

- Element 9.2 Collaborates with, and refers women to, appropriate community agencies and support networks.

Competency $10 \quad$ Ensures midwifery practice is culturally safe.

- Element 10.1 Plans, implements and evaluates strategies for providing culturally safe practice for women, their families and colleagues.

DOMAIN 4: REFLECTIVE AND ETHICAL PRACTICE

Competency 11 Bases midwifery practice on ethical decision making.

- Element 11.1 Practises in accordance with the endorsed Code of Ethics and relevant state/territories and federal privacy obligations under law.

Competency 12 Identifies personal beliefs and develops these in ways that enhance midwifery practice.

- Element 12.1 Addresses the impact of personal beliefs and experiences on the provision of midwifery care.

- Element 12.2 Appraises and addresses the impact of power relations on midwifery practice.

Competency 13 Acts to enhance the professional development of self and others. 
- Element 13.1 Assesses and acts upon own professional development needs.

- Element 13.2 Contributes to, and evaluates, the learning experiences and professional development of others.

Competency 14

_ Element 14.2 Interprets evidence as a basis to inform practice and decision making 


\section{References}

ACMI 2001a ACMI Competency Standards for Midwives. Canberra: Australian College of Midwives Inc.

ACMI 2001b Code of Ethics. Melbourne: Australian College of Midwives Inc.

ANC 2000 ANC National Competency Standards for the Registered Nurse (Vol. 2004). Canberra: Australian Nursing Council

ANMC 2006 National Competency Standards for the Midwife. Canberra: Australian Nursing and Midwifery Council

Brodie, P, Barclay, L 2001 Contemporary issues in Australian midwifery regulation. Australian Health Review, 24(4): 103-118

College of Midwives of Ontario 1994 Core Competencies of the College of Midwives of Ontario. Ontario: College of Midwives of Ontario

CRANA 2001 National Remote Area Nurse Competencies. Armidale: CRANA Inc

Cutts, D 1995 Midwifery competencies - Draft 2. ACMI Journal, 8(3): 11-13

Fullerton, J, Severino, R, Brogan, K, et al. 2003 The International Confederation of Midwives' study of essential competencies of midwifery practice. Midwifery, 19: $174-190$

Fullerton, J, Thompson, J 2005 Examining the evidence for the International Confederation of Midwives' essential competencies for midwifery practice. Midwifery, 21: 2-3

Glover, P 1999 ACMI competency standards for midwives - what they mean for your practice. ACMI Journal, 12(3): 12-17

Gonczi, A, Hager, P, Oliver, L 1990 Research Paper Number 1: Establishing Competency Based Standards in the Professions. Canberra: AGPS

Heywood, L, Gonzi, A, Hager, P 1992 Research Paper 7: A guide to the development of competency standards for the professions. Canberra: Department of Employment, Education and Training

ICM 2002 Essential competencies for midwifery practice. Geneva: International Confederation of Midwives

Leap, N 2000 A definition of 'woman-centred' midwifery practice. Prepared for the Nurses Registration Board of New South Wales. Sydney: UTS 
Midwifery Council of New Zealand 2004 Competencies for Entry to the Register of Midwives. Wellington: Midwifery Council of New Zealand

National Nursing and Nursing Education Taskforce 2005 Scopes of Practice Commentary Paper. Melbourne: The Australia Health Ministers' Advisory Council

Nursing and Midwifery Council. (2001, 27-July-2001). Midwifery Competencies. Retrieved 2-08-2004, 2004, from http://www.nmcuk.org/nmc/main/advice/midwiferyCompetencies.html

O Luanaigh, P, Carlson, C (Eds.). (2005). Midwifery and Public Health: Future Directions and New Opportunities. Edinburgh: Elsevier Churchill Livingstone.

Pearson, A, Fitzgerald, M, Walsh, K 2002 Nurses' views on competency indicators for Australian nursing. Collegian, 9(1): 36-40

Pearson, A, Fitzgerald, M, Walsh, K, et al. 2002 Continuing competence and the regulation of nursing practice. Journal of Nursing Management, 10: 357-364

Redfern, S, Norman, I, Calman, L, et al. 2002 Assessing competence to practice in nursing: a review of the literature. Research Papers in Education, 17(1): 51-77

Sandelowski, M 2000 Combining qualitative and quantitative sampling, data collection and analysis techniques in mixed method studies. Research in Nursing and Health, 23: 246-255

UNICEF 2002 Introducing the Baby Friendly best practice standards into breastfeeding education for student midwives and health visitors. London: UNICEF UK Baby Friendly Initiative,

WHO 1978 Primary Health Care International Conference on Primary Health Care Alma Ata, USSR, 6-12 September. Geneva: World Health Organization 